International Journal of Engineering \& Technology, 7 (1.9) (2018) 149-156
International Journal of Engineering \& Technology
WPC
Website: www.sciencepubco.com/index.php/IJET
Research Paper

\title{
Facial emotion detection technology: concept, marketing applications, business drivers and challenges
}

\author{
Joshi Sujata $^{1}$ *, Damle Madhavi ${ }^{1}$, Kumar Vishal ${ }^{2}$ \\ ${ }^{1}$ Associate Professor, Symbiosis Institute of Telecom Management, constituent of Symbiosis International \\ (Deemed University), Lavale, Pune \\ ${ }^{2}$ Student, Symbiosis Institute of Telecom Management, constituent of Symbiosis International (Deemed University), Lavale, Pune \\ *Corresponding author E-mail: sjoshi@sitm.ac.in
}

\begin{abstract}
The manuscript should contain an abstract. The abstract should be self-contained and citation-free and should not exceed 200 words. The abstract should state the purpose, approach, results and conclusions of the work. The author should assume that the reader has some knowledge of the subject but has not read the paper. Thus, the abstract should be intelligible and complete in it-self (no numerical references); it should not cite figures, tables, or sections of the paper. The abstract should be written using third person instead of first person.
\end{abstract}

\section{Introduction}

Facial Emotion Detection (FED) is an emerging trend in the space of marketing. The global market for emotion detection and recognition is expected to reach 36.07 Billion by 2021 at a CAGR of $39.9 \%$. [1]. the need to understand consumer behavior and the attempt to know their emotions concerning various events during purchase in a retail environment, have helped Facial recognition to come in the mainstream. From a marketing perspective, emotion detection provides real opportunities to drive customer spending and enhance loyalty. [2]. It has been observed that successful marketing campaigns carry emotional associations of consumers towards brands and hence emotions are indeed one of the major factors affecting consumer purchase decisions [3]. With the technological advent in the field of machine learning and deep learning, organizations have started experimenting with human to human interactions as well as human-computer interactions [4]. Facial expressions play an important role in measuring the level of interest of people when they interact with humans or machines [5]. Affective parameters in consumer behavior can affect user experiences hence FED techniques can find wide applicability in fields like behavioral science [6]. Facial recognition is a critical tenant for interpreting customer's facial expressions, human emotions, intentions, and behavior [7]. The potential for Facial recognition in the global market and within various types of organizations is colossal. FED finds applications in not just B2C companies but B2B companies as well for example companies like GE, Cisco, Qualcomm, IBM, AutoDesk etc. focus on emotions in their marketing [8]. The application of facial recognition is possible across industry verticals. The potential of the technology is creating need amongst organizations to adopt the technology. For research-based organization, the facial recognition system is considered as an addition, not a replacement to traditional research methodologies.

\section{Background literature}

Several papers have been published in the area of face emotion recognition for example Samal and Iyengar [9] focussed on early approaches to face recognition. Valentin et al.[10] were focussing on neural networks; Chellappa et al.[11] were focussing on psychophysics issues with respect to face recognition; Zhang et al.[12] focussing on Eigen face, neural networks and elastic matching. Seong et al [13] have focussed on the area of facial recognition techniques with specific reference to two dimensional images in the infra-red spectra. Yeasin \& Sharma [14], based on visual data collection have focussed on six types of facial expressions which are universal in nature adopting a spatio-temporal technique for facial expression recognition and measuring their levels of interest. Shergill et al [15] have suggested a framework for computerized sales assistant who analyses facial data of customers entering a shop which can be useful in various marketing areas such as product screening, product placement, marketing, advertising etc. Consoli [16] has studied the influence of emotions on purchase decision by using an algorithm of sentiment analysis for extracting and analysing opinion of online customers. Klaus R. Scherer and Ursula Scherer [17] have developed an emotion recognition index which consists of 2 tests, one which measures facial emotion and the other measuring voice recognition. Fuji Ren and Changqin Quan [18] have proposed a facial emotion and recognition method based on linguistics for measuring customer satisfaction. Aleix Martinez and Shichuan Du [19] have proposed a model in their study which can be used to build algorithms to understand facial expressions and emotions which will help in the study of human perceptions, interactions and disorders. Marketing Research Association whitepaper [20] discusses the applications of facial recognition technology in the field of marketing research such as measuring consumer emotions and interest, for eye tracking in the areas of retail, consumer goods, websites etc. Jan R. Landwehr et al [21] have expressed how the study of facial expressions can be used for product design by analysing consumer 
expressions and analysing whether they like the design of a product and if it influences sales of that product. P.M.A. Desmet [22] in his chapter on emotions measurement has introduced a production emotion measurement instrument which measures 14 types of emotions of consumers with respect to consumer products.

\section{Objective of paper}

It is imperative that consumers' purchase-related decisions are driven by emotion. But since Facial Recognition is an upcoming field, there is a dearth of academic research in this area. A lot of research had been done on the technological front, but limited research has been done in academic literature covering the business use-cases in marketing business, drivers and challenges with facial recognition as the backbone. Hence, this paper tries to build on the literature by exploring the following aspects related to the business case of FED in the marketing domain viz: (1) Concept of Facial emotion detection, (2) Applications of facial emotion detection in marketing field (3) Business Drivers and (4) Challenges associated with the facial emotion detection.

\section{Concept of facial emotion detection}

The concept of facial emotion detection has its roots in the studies conducted by Darwin [23] who was instrumental in suggesting the universal nature of emotions. His claims were later tested by Tomkins \& McCarter [24] in their studies wherein they tested and proved the association of facial expressions on some emotional state. The concept of Facial emotion detection and its universality was initially used by the psychologist Paul Ekman and his colleagues. [25] [26] [27] [28].They catalogued the activations of different facial muscles and how the muscles produced emotional expressions in 1970s. They develop Facial Action Coding System (FACS) with frequently occurring combinations of muscle movements creating facial action as the basic unit [29]. Paul Ekman argued that the six emotions viz. happiness, sadness, fear, disgust, surprise and anger begin involuntarily, which means that these emotions are triggered non-consciously and are more powerful than basic drives (e.g. food, procreation) because these six emotions can trump the basic drives.

Nielsen's press room blog [30] explains that as a result of facial emotions coding, distinct facial expressions of various emotions can be captured for example emotions of joy, surprise, sadness and confusion. A study by Nielsen [31] has showcased that there is a significant relationship between neuroscience and sales. Emotions have an important place in human perception and understanding [32] and hence facial expression of emotions can play a vital role in human communications [33]. Facial expressions are a resultant of muscular activities which take place due to the mental and emotional condition of a person and these lead to changes in the facial appearance which can be visually detected. [34]

Emotions are "specific sets of physiological and mental dispositions triggered by the brain in response to the perceived significance of a situation or object for an individual's goal."[35].Facial expression recognition can be connected to the fields of psychology and computations when combined with neuroscience and human psychology [16]. Examination of face and description of expression as combinations of action units (AUs), let organization know the emotion of the viewer." Imotions' pocket guide [36] explains the Facial Emotion Detection as a model for identifying facial expressions with the help of computers. It imitates the human expertise of coding as it assimilates all emotional responses for any content which may be raw and unfiltered.

Three tenants of Facial Emotion Detection are: a) Face detection Segmentation of face region based on automated face detection system; b) Feature detection - Extraction of information using feature extraction model; Extraction can be of exemplary features or feature groups; c) Feature classification - The information collected as output of feature detection stage is fed as input into clas- sification model to identify the emotion and other affective metrics.

Hence from the above definitions, we can describe Facial Emotion Detection as a business enabler which helps an organization know the emotion of their consumers using facial coding and thereby enhance the customer experience (CX) across industry verticals.

\section{Applications of facial emotion detection in marketing field}

The field of facial emotion detection is all set to bring about a major change in the area of marketing in the years to come. [37]. Dove's "Real Beauty" campaign, Nike's "Just Do It" campaign and MasterCard's "Priceless" campaigns are few examples which are focused on triggering emotions. As mentioned in the article by Miller [38], a senior marketing person from Google opines that "If we don't make you cry, we fail. It's about emotion." This section mentions the various applications of Facial Emotion Detection in the field of marketing with the help of use cases and also highlights the benefits accrued by using this technology.

\subsection{Advertisement}

As per the study conducted by Nielsen for 100 advertisements of 25 FMCG brands, results showcased that those ads which generated the best emotional responses resulted in raising the sales up to $23 \%$ [39]. Thus emotion based marketing is an engagement vehicle and a true business driver. Facial emotions find applicability in the area of advertising in the following ways.

\subsubsection{Adtech / ad testing (brand reveal and test voice-overs)}

Brand Reveal: Neuro-marketing principle suggests that if background music and text in the screen resonates then it will create a lasting impression in the mind of viewer. Thus, brand reveal can be scripted with text and the efficiency can be examined using facial emotion detection.

Voice-overs: It is a production technique where a voice that is not part of the narrative is used in an advertisement and filmmaking. Effect of voice over can be tested using facial emotion detection. In advertisement industry, the above FED techniques have a wide case application across industry verticals. Digital agencies and advertisement and media agencies can use emotion data to see if their audiences are emotionally involved at the moment of brand reveal in an ad and test the efficiency of taglines and voice-overs. Effective brand reveal and voice-over can help companies with top-of-the-mind recall and brand image retention amongst their customers.

Benefits: Thus FED helps in advertising by enhancing advertisement effectiveness, enhancing emotional involvement with brand, Top of mind recall, and Brand Image retention.

\subsubsection{A/B testing or split testing}

Understanding emotions has proved to be very effective in areas of research such as ad testing [2]. Facial emotion detection offers an opportunity to overcome limitations of human assessment by delivering a greater level of insight about personal sentiment and reactions [2]. Many large and well known organizations such as P\&G, Honda, Mars, Unilever, Coca Cola, Kellogg's etc. use emotion analysis to test audience reactions. Kellogg's used Facial Emotion Detection to do A/B testing for its ads for Crunchy Nut cereal. The audience was shown several versions of one of its commercials which featured animals. It was found in the study that the same ad but this time featuring an alien instead of animals showed higher levels of engagement. It was finally decided by Kellogg's to roll out the commercial featuring the alien. [37].

Advertisement and Digital agencies can use effective pre-launch strategies applying the hypothesis-based approach to avoid uncertainty. This type of Beta test will help know the emotional coefficient associated with the advertisement. Using emotion analytics, 
emotions for each moment in the ad can be analysed and thereby longer TV advertisements s can be cut to make shorter online advertisements. This may ensure that even if the length of the ad is shorter its impact is not lost. By applying the iterative loop, finally, the best ad can be launched.

Benefits: The above techniques will make advertisement testing easier and enhance efficiency of the ads.

\subsubsection{Ad placement}

The field of marketing and advertising has embraced the use of technology for capturing customer emotions and doing comprehensive analysis of the same. Various software tools such as face expression recognition, real-time emotion sensing applications, speech and voice recognition etc. are available for capturing the human emotions and help analysing them [40]. In Media channels like Netflix, Hot star, Hulu, Amazon Prime like platforms, the abrupt advertisements cause mood-swing amongst the viewer Enterprises are using multimedia channels to stimulate emotions in customer. The rationale of using multi channels is that different people can be receptive to different stimuli; some may respond to videos, some to graphs, some to audio etc. [16].

By applying facial emotion detection, the advertisement can be placed at run-time in such a way that it will enhance the experience rather than evoke a response of 'skip-ad' or ineffective ad This will, in turn, save the brand from revenue leakages. Facial emotion detection can help allocate media spend. The advertisements which evoke the best emotional responses after being viewed can be backed with higher media spend.

Benefits: The above FED techniques will result in Revenue Assurance, Avoid Revenue Leakage, and Enhance Return on investment in the ads.

\subsection{Experiential marketing}

\subsubsection{Testing augmented reality (AR) / virtual reality (VR) based application}

Emotional marketing is being used by organizations as a part of marketing strategy for building strong personalized relationships with the customers resulting in customer retention [16]. According to Forbes, augmented reality is becoming one of the hottest trends in the marketing and advertising industry. As indicated by Markets and Markets, AR market is projected to reach $\$ 117.4$ bn by 2022 [41]. Testing of virtual tours in Brick-And-Mortar based on augmented reality and testing the experience of test user can help enhance the experience of user.

Benefits: The above FED techniques will help to Enhance Customer Experience, and A/B testing at shop floor.

\subsubsection{Testing of immersive experience with packaging}

Augmented Reality (AR) enables product packaging to facilitate experiential brand interactions by superimposing a virtual element on top of a real product. Max Dawes, Marketing director, Zapper developed a baseball-theme based AR game whereby the consumer can scoop a 'zap code' on the pack and 'hit' balls pitched at them by a virtual pitcher.

Testing of packaging to resonate with consumers in the AR-based touchpoints can help the organization provide personalized experiences. Brands thus emerge as supply centres of emotional energy, building relationships with potential clients, and enriching consumers with stories which excite and integrate communication and brand sensitivity [16]. The testing of such AR based design concept using facial emotion detection can help organizations to entice consumers with more immersive experiences. Emotionally backed AR models can help grab the audience's attention, encourage a purchase by conveying a unique value proposition and could ensure fit with brand positioning.

Benefits: The above techniques will help in A/B Testing, testing Attractiveness of advertisement, and Testing Engagement levels of customers.

\subsection{Offline retail and online to offline $(\mathrm{O} 2 \mathrm{O})$ marketing strategies}

\subsubsection{Facial recognition based experiential service}

According to Artem Kukharenko, CEO, NTechLab (an Augmented Intelligence company), by using facial recognition in retail stores, visitors photos may function as cookies for identification thus making loyalty cards almost obsolete [42]. Moreover, as soon as customer walks in the store, the front-line salesperson will already know about the customer purchase history and thus provide experiential service.

In automotive industry, facial recognition with emotion-based Artificial Intelligence (AI) model can be integrated into supplier technology stack and Drive Assistance Systems. This will increase safety and enhance the in-cab experience. Integration with infotainment systems can provide personalized recommendations and adjustments based on mood of car's occupants.

Benefits: Thus the above techniques can result in Enhancing user experience, and providing personalized experiences to customers.

\subsubsection{CCTV based experiential marketing}

Experiential marketing becomes an important tool for brand revitalization in decline stages or for building a new brand identity or brand image ex-novo. It creates emotional involvement and positive experiences with the brand leading to creation of competitive advantage [16].

In 2015, as per a survey conducted on 150 retailers in UK, approximately a quarter of all shops in Britain are using facial emotion detection software [43]. Video intelligence software helps retail store with two issues - (i). Increase sales, (ii). Minimize loss. For example, retail stores like Saks use facial detection software which helps convert facial data into a biometric template which can then be referenced to match with database of shoplifters or criminals thus preventing revenue loss. The same data can be used to maximize sales by identifying customer dwell times and purchase locations etc. Some retailers, as well as top-end hotels, are using this software to identify celebrity and VIP guests or customers so that preferential treatment can be given to them to enhance customer experience.

A book-store chain in France had an in-store video fed to software which scrutinizes facial expressions of shoppers for understanding their emotions. If a customer, walks to the end of the aisle and the emotion found on his face is of disappointment, the software discreetly messages the salesperson who in turn walks up to the customer to help and provide assistance to him/her [44].

Benefits: The above techniques help in providing Increase in sales, detecting theft thus reducing revenue loss, Better Customer Service, Just in time assistance based on emotion, and Enhancing User experience.

\subsubsection{Integration with artificial intelligence (AI) enabled ro- bots}

AI backed robots are being developed to provide better customer experience in retail environment. One such robot is 'Mitra', built by Bengaluru-based Invento Robotics. Robots are getting programmed to greet customers and interacts using facial and speech recognition, contextual help, and autonomous navigation [45].The robot, "Mitra", is deployed in the branches of Canara Bank as well as PVR Cinema outlets in Bengaluru. The robots with technological integration of FED can help in queue management and better customer experience by helping customer in navigation.

Benefits: The above techniques help in creating Better Customer experience, in Queue Management, and Provide Contextual help.

\subsubsection{FED as audience measurement technology}

The facial emotion detection can help determine a shopper's age, gender and other basic demographics [46]. This data can then be 
marketed to retailers to help them with better managed campaigns and provide tailored on-screen advertisement to consumers.

According to a report by essentialretail.com, Tesco store plans to roll audience measurement technology backed by FED in its 450 petrol stations in UK [46]. As opined by Peter Cattell, category directory for the Tesco petrol stations, this software has the ability to customize the content based on time and location which will be prove helpful for customers as they can get content in proper time and at the required location.

Benefits: The above applications will provide Personalized Experience, and Better campaign management.

\subsubsection{Facial recognition and remarketing in online to offline (O2O)}

Retailers having presence in online as well as offline space can be benefited from facial emotion detection technology. Remarketing is a powerful tool used extensively by e-retailers. In offline store, the store people can capture what customers view in-store. If the customer leaves without making any purchase, the e-retailer can put similar products once again in front of them online with a personalized offer.

Benefits: The above application can enhance remarketing capability of a product.

\subsection{Online sales assistant}

The Facial Emotion Detection system can enhance the recommendation engine of e-retailers. If facial expression detection is given as an additional feature, it will tend to make the recommendation stronger. As the customer browses through the products of his/her need, the software scans the face and thus the emotion. The emotion will enrich the system for better suggestions.

Shergill, et al [15] designed a process flow which is a wonderful demonstration of how Facial emotion detection can be deployed as online sales assistant. As the customer enters the website of an eretailer, the e-retailers pop a request to the customer to switch on the webcam for providing additional assistance. If the customer is a new user and the facial emotion detection system notifies that the customer is not interested, then the backend system will not take any action. However, if the emotion recognized matches with someone who is mildly interested in product, the e-retailer backend system can provide similar recommendation and after continuously analysing the system can recommend the best buy option. Additionally, integration of data collected to the database is an integral part which should be tightly coupled with the facial emotion detection system.

Benefits: Such an application will help buyer make suitable choices, give recommendation for similar products and help in upselling or cross-selling of products.

\subsection{In-store sales assistant}

A sales assistant in-store, backed with facial emotion detection can give salespeople an indication about the type of shopper visiting the store [15]. It can be done by knowing (i) Who is the customer (ii) Past shopping history (iii) Recognition of facial expression. Based on the above factors, Shergill et al [15] proposed a process flow. As the customer enters the store, the camera/CCTV integrated with the facial emotion detection system analyses the face of the customer. If the customers face matches with the database, a trigger is passed on to the front line staff and the clerk approaches the customer. If the customer is uncomfortable with clerk, the FED system triggers another alert and the clerk leaves the customer alone.

On the other side, for a new customer, if the customer data is not available in the database, FED integrated camera analyses the face. If the customer emotion shows he/she is not interested and is just browsing, clerk takes no action. However, if the emotion of the customer seems to be like a possible customer, clerk will approach the customer and will try to close the sale.

Benefits: This technique will provide shopping assistance to customer and enhance customer shopping experience.

\subsection{Digital marketing}

Facial emotion detection can be used in digital marketing. Social media can be effectively used for understanding user's emotions. For example, Facebook's algorithm can focus on the users emotional reactions as much as it does on historical click behaviour of the user. [37].This will enhance user experience and provide a unique social environment. As a result, Facebook ads will be able to provide its advertisers with an opportunity to hyper target its customers based on their emotional states in addition to traditional age, geography, and job titles. Thus, FED will empower marketers to provide the correct message to correct individual at the correct time. Facebook is already working on incorporating use of emotions in the News feed. Apart from just "liking" Facebook is planning to provide six different emotions like Wow, Love, Angry, Ha-ha, and Sad and like.

Benefits: These applications will help in Digital Marketing, Social media analytics, for providing more number of touchpoints.

\subsection{Reverse billing for FED led survey}

Data is essential and is the new oil. Shoppers are sometimes asked to participate in research based on facial emotion detection, in exchange of discount or rewards. This emotion data in aggregation can help brick and mortar shop to improve displays, music, content, packaging and timing of sales pitches. This is different from traditional survey because in normal pen/paper-based survey, respondents alter their comment to sound rational. By using FED, researchers can collect relevant psychographic data of customers at lesser costs vis a vis other modes of data collection. Thus, FED creates an opportunity for marketers to understand the in-depth needs of the customer.

Benefits: these applications will benefit for sales pitching, improving display/packaging and understanding in-depth needs of customers.

\section{Business drivers of fed}

All the factors and conditions which are necessary for the success of facial emotion detection viz. integration with IT services, integration with other neuro-marketing tools, device ecosystem, reverse billing concept and regulation free environment comes under business drivers. We have captured the business drivers by showcasing the same in the below mentioned figure 1 . 


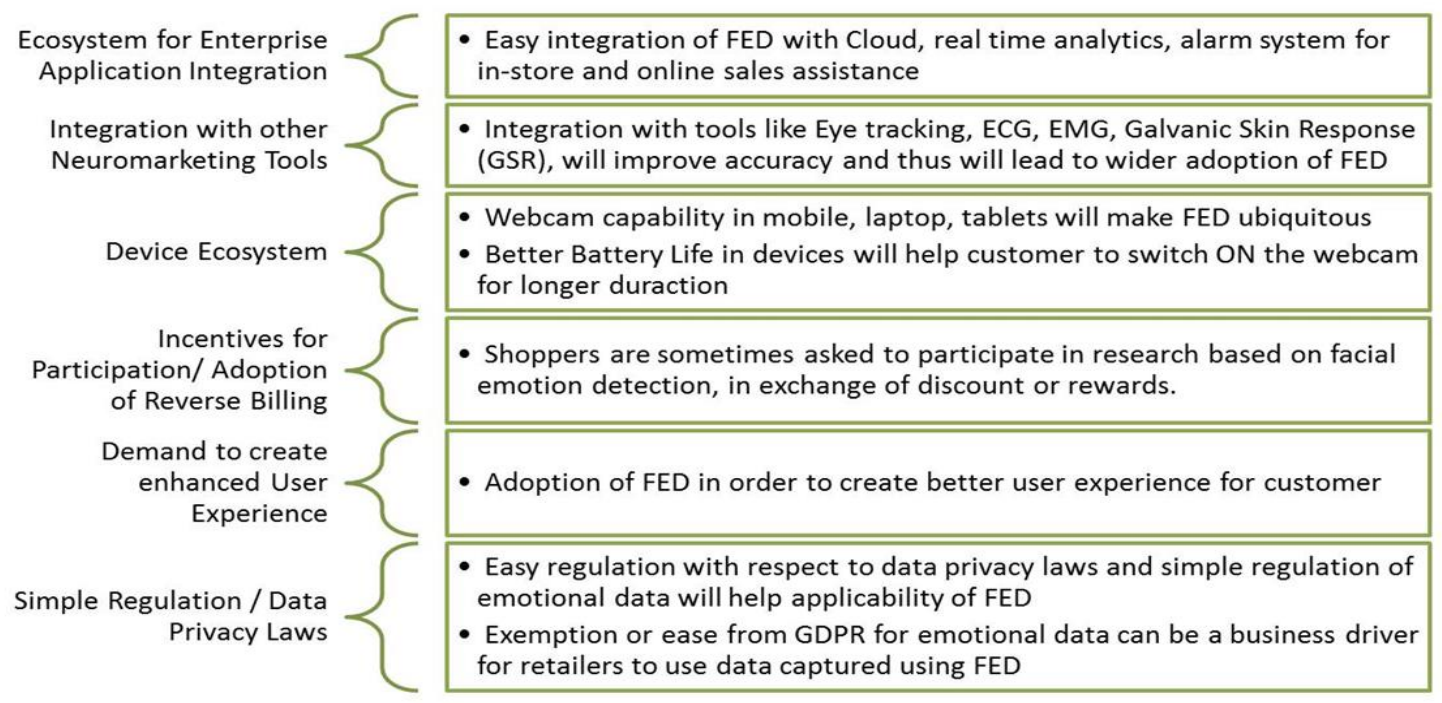

Fig. 1: Business Drivers for Facial Emotion Detection.

\section{Challenges associated with fed}

\subsection{Accuracy}

Achieving high level of accuracy in facial expression recognition area is a very challenging task even for humans who are experts in this area [47] [14]. So one can imagine the difficulty levels in predicting human facial expression using machines. The entire process chain needs to be upgraded to support reliable results.

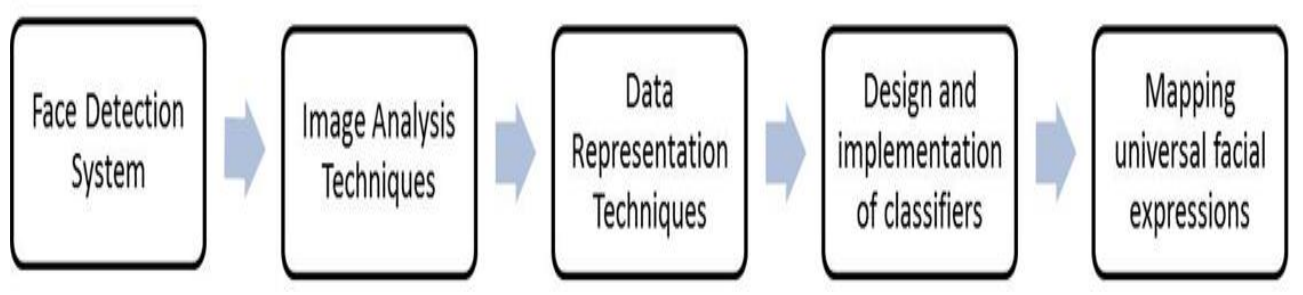

Fig. 2: FED Process Chain.

The above mentioned process components (refer figure 2) need to be backed with high mathematical models with the help of Artificial Intelligence for high accuracy. Further information related to age, race and gender can be used to improve the accuracy [48]. In Facial Emotion Detection, a major challenge is that the number of possible face classifications is very large but the number of images which are available for training are comparatively smaller [48]. Additionally, the system and models in the process have to be robust to absorb typical problems related to image acquisition such as noise, video-camera distortion, and image resolution [48].

\subsection{Challenges pertaining to recognition}

Problems related to out-of-plane head motion, change of scale and varied lighting conditions can provide situations where it is difficult to recognize emotion by using Facial Emotion Detection [14]. Complexities in facial emotion detection differ based on illumination intensity, inclination, type of pose, noise present, pertaining to the still images as well as video images [49]. Performance of visual face recognition is sensitive to variations in illumination conditions [48]. One example where Facial Emotion Detection can be tough to identify emotion is situations where people express emotions while speaking. In such cases the speech deformities can mistakenly be classified as main emotion instead of the actual emotion depicted [14]. Identification of individuals with makeup or disguise becomes difficult using visual face detection techniques [48]. A thermal Infrared (IR) based face recognition reveals robust thermal characteristics of the face regardless of ambient illumination. However, it is difficult to identify individuals by thermal imaging if they wear glasses or if they are seated in a moving vehicle [48].

\subsection{Ethical approach}

The decisions of customers are driven by two kinds of needs - (i). Functional needs and, (ii). Emotional needs [16]. The product must generate emotions but also present good utilitarian value. Thus it is very important to note that as per the ethical approach the basic product or service must be manufactured with total rigor, efficiency and good spirit. Emotions are to be treated as an add-on which will enhance the features of the existing product or service. Emotions should not be used as an alternative to push substandard or poor products or mask their limitations.

\subsection{Pretense}

Another weakness of Facial Emotion Detection can be pretense [16]. Pretense is defined as the case where an individual's facial expression does not correspond to his/her true psychological state [16]. Some consumers may be able to mask their real emotions and pretend to emote differently. This may have an adverse effect on the results as the pretended emotions and not the real emotions will be recorded.

\subsection{Globalization of emotions}

Customers who will be observed as part of FED may be across the globe. They may belong to different countries having different nationalities, different cultures and also different face structures. Hence their emotional responses may differ thus necessitating the need for benchmarks for such data. [2]. 


\subsection{Customer's willingness to permit access of data}

One more major challenge faced by organizations deploying facial emotion detection system is to seek the permission of customers or the respondents for accessing their web cameras, and for recording their expressions when they watch the content showcased to them [2]. Many customers may be unwilling for recording of this sort as they feel it's a intruding their privacy.

\subsection{Challenges associated with two-way communication}

Facial emotion detection technology needs two-way communication. This means that respondents must be seated in such a position that they are able to view the content clearly and where the web camera is able to capture their expression whilst they view this content [2]. In real-time facial emotion detection, connectivity is important to mitigate this challenge and telecom will play a larger role.

\section{Conclusion}

Facial Emotion Detection is an active research field due to its potential use in marketing and other commercial applications. There are numerous uses of facial emotion detection in all the spheres of life. It can be used in Advertising for Ad testing and Ad placement. In the area of experiential marketing it can be used for enhancing customer experience and testing engagement levels. It can be used in offline and $\mathrm{O} 2 \mathrm{O}$ strategies to enhance user experience and improve just in time assistance. It can be used for sales purpose with help of online sales assistants or even used instore for enhancing sales efficiency. Finally it can be useful for digital marketing strategies for enhancing customer engagement.

Figure 3 below captures a summary of the entire paper. This paper explores the concept of facial emotion detection, the business applications of FED especially in marketing domain, the business drivers of FED and the challenges associated with the implementation of this technology initiative.

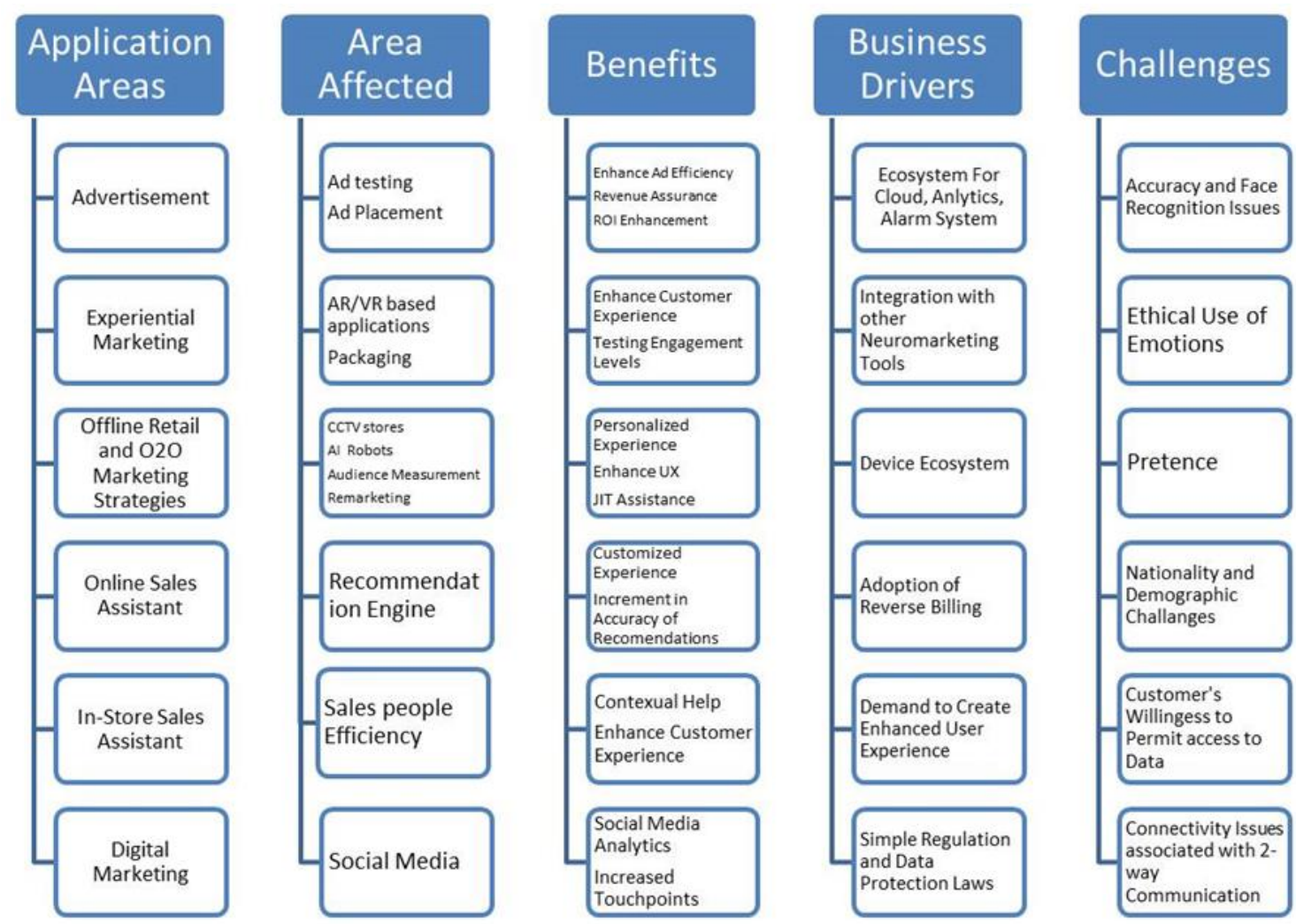

Fig. 3: Applications, Areas, Benefits, Business Drivers and Challenges of FED.

\section{Managerial implications}

The concept of the paper has direct benefit to e-retailers and can also be used for offline modes where face image captures are possible. The application of facial emotion detection in various processes has definitive advantage to their tactical deployment on day to day operations and these can have major impact as data points even in the strategic stance.

As for 'brick and mortar' stores the study will help them understand how to enhance enhanced user experience due to customer presence as added advantage versus proxy. The impacts has implications on strategic level for customer retention, value addition and customer delight by the sheer force of the knowledge of" what you are thinking!" as a customer.

The applications discussed in this paper can be provided as managed services by organizations that have developed niche with various intellectual properties in the area of facial emotion detection technology.
Finally this paper will also be helpful to marketers for understanding and implementing FED as a neuro-marketing tool. The insights from this paper will help them devise marketing strategies by customizing their advertising and communication based on customer emotions. They can enhance their product and brand management strategies by customizing product and packaging to suit customer requirements. It will also help them in churn management and customer retention strategy. At a strategic level, the insights of the paper can be used by marketers to create competitive advantage for their organization.

\section{References}

[1] Marketsandmarkets.com report. Emotion Detection and Recognition Market by Technology (Bio-Sensor, NLP, Machine Learning), Software Tool (Facial Expression, Voice Recognition), Service, Application Area, End User, and Region - Global Forecast to 2021 December (2016). Retrieved on $19^{\text {th }}$ December 2017 from https://www.marketsandmarkets.com/Market-Reports/emotiondetection-recognition-market-23376176.html. 
[2] Lawlor, Terry. Facial Recognition in Retail Market Research the Next Big Thing? February $14^{\text {th }} 2017$. Retrieved on $19^{\text {th }}$ December (2017) from https://www.chainstoreage.com/article/facialrecognition-retail-market-research-next-big-thing/

[3] Rick Miller .Understanding Consumers' Emotional Fingerprint: Why Sentiment Is Misleading. March 27 ${ }^{\text {th }}$ (2015).

Retrieved on $19^{\text {th }}$ December 2017 from https://marketingland.com/understanding-consumers-emotionalfingerprint-sentiment-misleading-122267.

[4] Bebawy, M. Anwar, S. Milanova, M .Active Shape Model vs. Deep Learning for Facial Emotion Recognition in Security, Cham Switzerland; Cancun Mexico: Springer International, Switzerland, pp. 1-11, (2017).

[5] K. Matsumura, Y. Nakamura, and K. Matsui, "Mathematical representation and image generation of human faces by metamorphosis," Electron.Commun. Jpn. vol. 80, pp. 36-46, (1997). https://doi.org/10.1002/(SICI)1520-6440(199701)80:1<36::AIDECJC4>3.0.CO;2-5.

[6] M. Pantic and L. J. M. Rothkrantz, "Automatic analysis of facia expressions: the state of the art," IEEE Trans. Pattern Anal. Mach Intell., vol. 22, pp. 1424-1445, (2000). https://doi.org/10.1109/34.895976.

[7] Kong, S. G., Heo, J., Abidi, B. R., Paik, J., \& Abidi, M. A. Recent advances in visual and infrared face recognition - A review. Computer Vision and Image Understanding, 97(1), 103-135, (2005). https://doi.org/10.1016/j.cviu.2004.04.001

[8] Gregory Ware (Digital Marketing Blog). How Emotion-Detection Technology Will Change Marketing. ?. October 17 $7^{\text {th }}$ (2017). Retrieved on $19^{\text {th }} \quad$ December 2017 from https://gregorycware.wordpress.com/tag/hubspot-marketingblog/page/87/.

[9] A. Samal, P.A. Iyengar Automatic recognition and analysis of human faces and facial expressions: a survey, Patt. Recogn. 25 (1), 65-77, (1992). https://doi.org/10.1016/0031-3203(92)90007-6.

[10] D. Valentin, H. Abdi, A.J. O_Toole, G.W. Cottrell, Connectionist models of face processing: a survey, Patt. Recogn. 27 (9), 12091230, (1994). https://doi.org/10.1016/0031-3203(94)90006-X

[11] R. Chellappa, C.L. Wilson, S. Sirohey, Human and machine recognition of faces: a survey, Proc.IEEE 83 (5) 705-740, (1995). https://doi.org/10.1109/5.381842.

[12] J. Zhang, Y. Yan, M. Lades, Face recognition: Eigen face, elastic matching, and neural nets, Proc.IEEE 85 (9), 1423-1435, (1997). https://doi.org/10.1109/5.628712.

[13] Seong G. Kong, Jingu Heo, Besma R. Abidi, Joonki Paik, and Mongi A. Abidi (2004). Recent advances in visual and infrared Face recognition - a review. Computer Vision and Image Understanding 97,103-135, https://doi.org/10.1016/j.cviu.2004.04.001

[14] Yeasin, M., Bullot, B., \& Sharma, R. Recognition of facial expressions and measurement of levels of interest from video. IEEE Transactions on Multime dia. https://doi.org/10.1109/TMM.2006.870737.

[15] Shergill et al .Computerized Sales Assistants: The Application of Computer Technology to Measure Consumer Interest - A Conceptual Framework. Journal of Electronic Commerce Research, VOL 9, NO 2, (2008).

[16] Consoli, D. Emotions that Influence Purchase Decisions and their Electronic Processing. Annales Universitatis Apulensis Series Oeconomica, 11(2), pp 996-1008, (2009).

[17] Klaus R. Scherer and Ursula Scherer. Assessing the Ability to Recognize Facial and Vocal Expressions of Emotion: Construction and Validation of the Emotion Recognition Index. Nonverbal Behav https://doi.org/10.1007/s10919-011-0115-4.

[18] Fuji Ren and Changqin Quan. Linguistic-based emotion analysis and recognition for measuring Consumer satisfaction: an application of affective computing. Inf Technol Manag (2012) 13:321-332.

[19] Aleix Martinez and Shichuan Du. Model of the Perception of Facial Expressions of Emotion by Humans: Research Overview and Perspectives. Journal of Machine Learning Research 13 (2012) 1589 1608, (2012).

[20] Marketing Research Association whitepaper. The Marketing Research Applications of Facial Recognition Technology. (February 06, 2014). Retrieved on 21t December 2017 from https://www.insightsassociation.org/sites/default/files/misc_files/mr a_facial-recognition-mr-applications_2-6-14.pdf.

[21] Jan R. Landwehr, Ann L. McGill, \& Andreas Herrmann. It's got the Look: The Effect of Friendly and Aggressive "Facial" Expressions on Product Liking and Sales. Journal of Marketing Vol. 75 (May 2011), $132-146,(2016)$
[22] P.M.A. Desmet (in press). Measuring Emotions. To be published in: M.A. Blythe, A.F. Monk, K. Overbeeke, \& P.C. Wright (Eds.), Funology: from usability to enjoyment.

[23] Darwin, C. The expression of emotion in man and animals. New York: Oxford University Press. (1872) https://doi.org/10.1037/10001-000.

[24] Tomkins, S. S., \& McCarter, R. What and where are the primary affects? Some evidence for a theory. Perceptual and Motor Skills, 18(1), 119-158, (1964). https://doi.org/10.2466/pms.1964.18.1.119.

[25] Ekman, P. Universal and cultural differences in facial expression of emotion. In J. R. Cole (Ed.), Nebraska Symposium on Motivation, Vol. 19, pp. 207-283. Lincoln, NE: Nebraska University Press, (1971).

[26] Ekman, P. (Ed.). Darwin and facial expression; a century of research in review. New York: Academic Press, (1973).

[27] Ekman, P., \& Friesen, W. V. Constants across culture in the face and emotion. Journal of Personality and Social Psychology, 17 124-129, (1971). https://doi.org/10.1037/h0030377.

[28] Ekman, P., Sorenson, E. R., \& Friesen, W. V. Pan cultural elements in facial displays of emotion. Science, 164(3875), 86-88, (1969). https://doi.org/10.1126/science.164.3875.86.

[29] P. Ekman and W.V. Friesen, "Manual for the Facial Action Coding System," Consulting Psychologists Press, (1977).

[30] Nielsen's press room blog. Facial Expression Analysis: The Complete Pocket Guide. February $19^{\text {th }}(2016)$. Retrieved on $21^{\text {st }}$ December 2017 from https://imotions.com/blog/facial-expressionanalysis/.

[31] Nielsen (Article). Nielsen Consumer Neuroscience Unveils Trailblazing Ad Testing Solution. Jun 13, (2016). Retrieved on $21^{\text {st }}$ December 2017 from https://www.prnewswire.com/newsreleases/nielsen-consumer-neuroscience-unveils-trailblazing-adtesting-solution-300283682.html

[32] A. R. Damasio. Descartes' Error: Emotion, Reason, and the Human Brain. G. P. Putnam's Sons, New York, (1995).

[33] K.L. Schmidt and J.F. Cohn. Human facial expressions as adaptations: Evolutionary questions in facial expression. Yearbook of Physical Anthropology, 44:3-24, https://doi.org/10.1002/ajpa.20001.

[34] P. Ekman, W. Friesen, Facial Action Coding System, Consulting Psychologists Press, Palo Alto, Calif., (1977).

[35] Ann Iren Jamtøy (Working paper). "Emotion and cognition in political communication". Paper for the 3rd International Conference on Democracy as Idea and Practice, Oslo, 12-13 January (2012). Retrieved on $21^{\text {st }} \quad$ December 2017 from http://www.uio.no/english/research/interfaculty-researchareas/democracy/news-and-events/events/conferences/2012/papers2012/Jamtoey.-wshop1pdf.pdf

[36] Imotions Pocket Guide. Facial Expression Analysis. (2016). Retrieved on $21^{\text {st }}$ December 2017 from https://imotions.com/wpcon-

tent/uploads/Guides/iMotions_Guide_FacialExpressions_2016.pdf

[37] Shapiro Tom (Blog). How Emotion-Detection Technology Will Change Marketing. October 5, (2017). Retrieved December 20, 2017, from https://blog.hubspot.com/marketing/emotion-detectiontechnology-marketing

[38] Miller Claire Cain (Article). Google Bases a Campaign on Emotions, Not Terms. January 1 (2012). Retrieved on $23^{\text {rd }}$ December 2017 from http://www.nytimes.com/2012/01/02/technology/googlehones-its-advertising-message-playing-to-emotions.html.

[39] Brandt David (Article). Emotions Give Lift to Advertising. (2016). Retrieved on $24^{\text {th }} \quad$ December 2016 from http://www.nielsen.com/content/dam/nielsenglobal/us/docs/solution s/emotions-give-a-lift-to-advertising.pdf

[40] Research and Markets (Report) \$22 Billion Emotion Detection and Recognition Market 2016-2020 by Technology, Software Tools, Services, Application Areas \& End Users. February 02 (2016) Retrieved on $24^{\text {th }} \quad$ December 2017 from https://globenewswire.com/newsrelease/2016/02/02/806969/0/en/22-Billion-Emotion-Detectionand-Recognition-Market-2016-2020-by-Technology-SoftwareTools-Services-Application-Areas-End-Users.html.

[41] DQIndia Online (Article). Digital advertising trends in India v/s International market. March 21, (2017). Retrieved on $24^{\text {th }}$ December from http://www.dqindia.com/digital-advertising-trends-inindia-vs-international-market/

[42] Allegretti Matt (Article). Facial Recognition Technology Is Turning Heads in Advertising. October 3 (2017). Retrieved on $24^{\text {th }}$ December 2017 from https://medium.com/dumbstruck/facial-recognitiontechnology-is-turning-heads-in-advertising-3f932c64f21e. 
[43] Frey Chris (Article). Revealed: how facial recognition has invaded shops - and your privacy. March 3 (2016). Retrieved on $24^{\text {th }}$ December 2017

from https://www.theguardian.com/cities/2016/mar/03/revealed-facialrecognition-software-infiltrating-cities-saks-toronto.

[44] The Economist (Article). "How retailers are watching shoppers" emotions". June 8 (2017). Retrieved on $24^{\text {th }}$ December 2017 from https://www.economist.com/news/business/21723162-cctv-thermalimaging-cameras-eeg-caps-and-other-kit-boost-sales-how-retailersare-watching

[45] D'Mello Gwyn (Article). Meet Mitra, The 5-Foot Made-In-India Robot That Greeted PM Modi And Ivanka Trump At GES 2017. November 29 (2017). Retrieved on 24 ${ }^{\text {th }}$ December 2017 from https://www.indiatimes.com/technology/news/meet-mitra-the-5foot-made-in-india-robot-that-greeted-pm-modi-and-ivanka-trumpat-ges-2017_-334629.html

[46] Sillitoe Ben (Article). Tesco first to roll out Amscreen's facial recognition technology. November 4 (2013). Retrieved on $24^{\text {th }}$ December 2017 from http://www.essentialretail.com/in-storeops/article/5277752c6477d-tesco-first-to-roll-outamscreen $\%$ E2\%80\%99s-facial-recognition-technology

[47] C. L. Lisetti and D. J. Schiano, "Automatic facial expression interpretation: where human-computer interaction, artificial intelligence and cognitive science intersect," Pragmatics \& Cognition, vol. 8, pp. 185-235, May (2000).

[48] Kong, S. G., Heo, J., Abidi, B. R., Paik, J., \& Abidi, M. A. Recent advances in visual and infrared face recognition - A review. Computer Vision and Image Understanding, 97(1), 103-135. https://doi.org/10.1016/j.cviu.2004.04.001.

[49] Dutta, P. Nachamai, N. "A Contemplation of Facial Expression Recognition System in Real World Applications". International Journal of Advances in Electronics and Computer Science, Volume-2, Issue-9, pp 13-18, (2015). 